\title{
Feeding ecology and laboratory predatory behavior toward live and artificial moving prey in seven rodent species
}

\author{
WILLIAM TIMBERLAKE and DONNA L. WASHBURNE \\ Indiana University, Bloomington, Indiana
}

\begin{abstract}
The present research related the feeding ecology of seven rodent species to the reactions of laboratory-reared and prey-inexperienced members of each species both to live prey and to an artificial moving stimulus predicting food pellets. Feeding ecology was determined by the degree of carnivory, based on reported stomach contents and observations of feeding. Experiment 1 assessed predatory reactions to a live cricket placed in each animal's home cage. Killing and latency of eating the cricket were directly related to the degree of reported carnivory on moderately fast-moving arthropods. Experiment 2 examined behavior toward a rolling ball bearing that predicted delivery of food. Average percentages of trials with approach or contact of the bearing, and the conditional probability of a mouth contact were all positively related to the degree of reported carnivory and to cricket predation in Experiment 1 . In addition, the topography of ball bearing contact for a species often resembled its topography of cricket contact. We conclude that (1) rodent predatory behavior can be studied in the laboratory using appropriate artificial stimuli and prey-inexperienced subjects, and (2) the predatory behavior of a species is based on underlying appetitive organization related to carnivory, including differential sensitivity to stimulus movement, motor preorganization, and susceptibility to conditioning. This appetitive organization appears to influence responding to both live and artificial prey.
\end{abstract}

Prey-naive laboratory rats (Rattus norvegicus) interact vigorously with a rolling ball bearing that predicts the delivery of food (Boakes \& Jeffery, 1979; Timberlake, 1983a; Timberlake, Wahl, \& King, 1982). The responses directed to the bearing resemble those shown by rats in predation on insects, including digging, chasing, seizing, carrying, retrieving, biting, and turning in the forepaws (Karli, 1956; Timberlake, personal observation, 1977). In short, rats appear to treat the moving bearing as a prey item, a conclusion also supported by the effect of previous poisoning in preventing eating but not predatory responses to the bearing (Timberlake \& Melcer, 1988).

Timberlake and Melcer (1988) argued that their results show that the determinants of predatory behavior can be studied in the laboratory using artificial rather than live prey. Timberlake $(1983 a, 1983 b, 1984)$ and Timberlake and Lucas (in press) further argued that such organized predatory reactions to artificial stimuli by preyinexperienced rats reflect the contribution of an underlying species-typical, food-getting organization to the results of conditioning procedures. Such an appetitive organiza-

This research was supported by National Science Foundation Grants 82-10139 and 84-11445. We thank Frank Adams and James Dougan for assistance in analysis, Moshe Yuchtman for his translation, and Valeri Dougan and Gary Lucas for critical comments. We are especially indebted to David Gubernick, John King, Elise Steinberg, Miwako Tamura, and Connie Warner for assistance with obtaining the rodents. Reprint requests should be directed to $W$. Timberlake, Department of Psychology, Indiana University, Bloomington, IN 47405. tion (or behavior system; see Tinbergen, 1951) is presumed to include differential sensitivity to particular stimulus characteristics, preorganized response components, motivational processes, and susceptibility to modification by experience (Timberlake \& Lucas, in press). Thus, rats treat a rolling ball bearing that predicts food as a prey item because, given the feeding system of the rat, the bearing has sufficient prey characteristics to support predatory behavior (e.g., movement, size, and spatiotemporal relation to food).

It follows from these arguments that the appetitive structure underlying the feeding ecology of a species can be studied in the laboratory, even in prey-inexperienced animals. Furthermore, the appetitive structure characteristic of a species should influence both the effectiveness of artificial moving stimuli in producing predatory responses and the topography of the resultant responses. Members of species that commonly attack and consume moving prey should show more extensive and complex predatory reactions to both live and artificial prey stimuli than should less carnivorous animals. In addition, the topography of behavior directed by a species toward an artificial moving stimulus should resemble responses typically involved in the capture and handling of live, moving prey.

The purpose of the present research was to test these predictions for seven species of rodents by determining the relations among degree of reported carnivory and the reactions of laboratory-reared, prey-inexperienced members of these species to live crickets and to moving ball bearings. Our first hypothesis was that the extent of preda- 
tory responses to live crickets and rolling ball bearings should be directly related to each other and to the degree of reported carnivory on prey with comparable stimulus characteristics (i.e., moderately fast-moving prey). Because nearly every rodent species is to some degree an omnivore (Landry, 1970), we expected some prey interaction in all species. However, we anticipated a marked difference in the extent of predatory responses between the more and less carnivorous species, and significant rank-ordered correlations among cricket killing, extent of bearing interaction, and degree of reported carnivory.
Our second hypothesis was that aspects of the topography of responses to the ball bearings should resemble the topography of predatory responses to the crickets. For example, if a species typically seized a cricket with the front paws, we expected a moving ball bearing also to be seized with the paws. On the other hand, if live prey items were seized first with the mouth, we expected the ball bearing to be seized first with the mouth.

Experiment 1 related the reactions of the different species to individual crickets dropped into each animal's home cage with the species' degree of reported carnivory.

Table 1

Animal Matter Eaten by Species Based on Stomach Contents and Observations

\begin{tabular}{|c|c|c|c|}
\hline \multirow[b]{2}{*}{ Species } & \multicolumn{3}{|c|}{ Type of Animal Prey } \\
\hline & Minimal Movement & More Movement & Sources \\
\hline O. leucogaster & $\begin{array}{l}\text { grubs } \\
\text { insect eggs } \\
\text { caterpillars }\end{array}$ & $\begin{array}{l}\text { ants } \\
\text { leaf hoppers } \\
\text { locusts } \\
\text { beetles } \\
\text { crickets } \\
\text { grasshoppers } \\
\text { spiders } \\
\text { scorpions } \\
\text { reptiles } \\
\text { birds } \\
\text { mammals }\end{array}$ & $\begin{array}{l}\text { Flake (1973) } \\
\text { Horner, Taylor, \& Padykula (1965) }\end{array}$ \\
\hline P. californicus & - & $\begin{array}{l}\text { arthropods } \\
\text { mice } \\
\text { birds }\end{array}$ & Merritt (1974) \\
\hline P. maniculatus & $\begin{array}{l}\text { insect eggs } \\
\text { insect larvae } \\
\text { caterpillars } \\
\text { earth worms } \\
\text { slugs } \\
\text { grubs }\end{array}$ & $\begin{array}{l}\text { ants } \\
\text { grasshoppers } \\
\text { diptera } \\
\text { butterflies } \\
\text { crickets } \\
\text { spiders } \\
\text { beetles } \\
\text { millipedes } \\
\text { mice } \\
\text { salamanders }\end{array}$ & $\begin{array}{l}\text { Flake (1973) } \\
\text { Hamilton (1941) } \\
\text { Houtcooper (1978) } \\
\text { Whitaker (1966) } \\
\text { Wolff, Dueser, \& Berry (1985) }\end{array}$ \\
\hline P. leucopus & $\begin{array}{l}\text { grubs } \\
\text { caterpillars } \\
\text { insect larvae } \\
\text { insect eggs } \\
\text { earth worms } \\
\text { slugs } \\
\text { snails } \\
\text { sow bugs }\end{array}$ & $\begin{array}{l}\text { ants } \\
\text { diptera } \\
\text { crickets } \\
\text { bees } \\
\text { flies } \\
\text { hemiptera } \\
\text { millipedes } \\
\text { beetles } \\
\text { centipedes }\end{array}$ & $\begin{array}{l}\text { Hamilton }(1941) \\
\text { Whitaker }(1963,1966)\end{array}$ \\
\hline M. unguiculatus & - & $\begin{array}{l}\text { grasshoppers } \\
\text { crickets }\end{array}$ & $\begin{array}{l}\text { C. J. Brack (1981) } \\
\text { G. L. Brack (1981) } \\
\text { S. Hopp (personal communication, 1982) } \\
\text { Schwentker (1979) }\end{array}$ \\
\hline A. cahirinus & $\begin{array}{l}\text { camel excrement } \\
\text { goat excrement } \\
\text { dead animal matter } \\
\text { snails } \\
\text { caterpillars }\end{array}$ & spiders & $\begin{array}{l}\text { Harrison (1972) } \\
\text { Shkolnik (1966) }\end{array}$ \\
\hline S. hispidus & $\begin{array}{l}\text { dead animal matter } \\
\text { quail eggs }\end{array}$ & beetles & $\begin{array}{l}\text { Hendrickson (1983) } \\
\text { Kincaid \& Cameron (1982) } \\
\text { Meyer \& Meyer (1944) }\end{array}$ \\
\hline
\end{tabular}

Note-Entries imply occurrence only, not relative frequency. We assumed that except in the case of $O$. leucogaster and possibly $\boldsymbol{P}$. californicus, all vertebrates were eaten as carrion. A dash indicates that no instance was reported. 
Experiment 2 compared the reactions of the different species to a ball bearing that marked food delivery with the degree of reported carnivory and the latency and topography of cricket attack.

\section{ESTIMATED DEGREE OF CARNIVORY}

The seven rodent species varied from highly carnivorous (Onychomys leucogaster), through omnivorous (Peromyscus californicus, $P$. maniculatus, $P$. leucopus), to more herbivorous (Meriones unguiculatus, Acomys cahirinus, Sigmodon hispidus). The degree of carnivory was estimated from a compilation of field reports of stomach contents and observations of feeding behavior. Table 1 shows the resultant list of animal matter consumed by each species. We attempted to supplement these qualitative data with quantitative comparisons of stomach contents, but were largely unsuccessful. Comparisons were difficult because stomach contents were measured in several different ways, the distribution of available prey varies markedly with habitat and time of year, and no data were found for $A$. cahirinus and $M$. unguiculatus.

On the basis of Table 1 and the sources listed at the bottom of the table, we arranged the species from most to least carnivorous. We placed first the highly carnivorous $O$. leucogaster (the grasshopper mouse). Most of the vegetable matter ingested by these mice is probably a by-product of catching herbivorous insects (Flake, 1973). Because of a relative lack of data, $P$. californicus (the California mouse) was more difficult to rank and was placed alternatively second and fourth. The mouse was placed second because the stomachs of every specimen described by Merritt (1974) contained arthropod remains, the amount of which varied sharply with habitat, suggesting that predation was strongly limited by prey availability. The alternative ranking of fourth was defended on the relative total animal matter ingested.

$P$. maniculatus (the deer mouse) and $P$. leucopus (the white-footed mouse) were placed next. $P$. maniculatus was ranked higher because Wolff, Dueser, and Berry (1985) showed that this mouse had the larger percentage of arthropod remains across all seasons, and it appeared to be the more flexible in initial responding to variations in food supply (see also Drickamer, 1972; Kreiter \& Timberlake, 1988). M. unguiculatus (the Mongolian gerbil) and $A$. cahirinus (the Egyptian spiny mouse) were placed lower than the three Peromyscus species because there were very few or no reports of their taking fast-moving arthropods. $M$. unguiculatus was ranked above $A$. $c a-$ hirinus because the former has been seen taking grasshoppers (S. Hopp, personal communication, June 1982) and crickets (C. J. Brack, 1981; G. L. Brack, 1981), whereas the latter has been observed taking only softbodied and/or slower moving insects. S. hispidus was placed last because there were no reports of its taking moving prey.

\section{EXPERIMENT 1}

The purpose of Experiment 1 was to determine the extent and topography of the interaction of each rodent species with live crickets and to relate that interaction to reports of carnivory on moderately fast-moving and evasive prey. Crickets were selected as prey because of their widespread distribution in the natural environment and their ready availability to the experimenter. A single cricket was presented to 6 prey-inexperienced adult members of each species in their home cages. We recorded whether the cricket was killed, and whether and with what latency eating began. Previous research with $P$. maniculatus and $P$. leucopus showed that a single cricket presentation in the home cage was sufficient to determine species and individual differences in frequency and latency of attack (Kreiter \& Timberlake, 1988). Subsequent crickets were presented here to clarify details of the attack topography.

\section{Method}

Subjects. The subjects were all adult rodents, ranging in age from 6 months to 1 year, distributed across species and sex as shown in the first two columns of Table 2. All subjects were reared in the laboratory and were prey naive except that $2 O$. leucogaster had previously encountered one cricket each in a small open field. This experience did not seem critical to the results inasmuch as these mice had the second and fifth fastest latencies to kill the cricket among the $6 O$. leucogaster. All subjects were housed under a 12:12h light:dark cycle in individual plastic cages. Temperature was controlled at $20^{\circ} \mathrm{C}$. Each cage was $20 \times 30 \times 10 \mathrm{~cm}$ and was filled to a height of $2-3 \mathrm{~cm}$ with wood shavings. The animals were fed laboratory chow, with occasional supplements of millet and sunflower seeds, and were food deprived for $6 \mathrm{~h}$ before testing, which occurred in the middle to late afternoon.

Apparatus. Testing in the animal's home cage was done by removing the wire mesh top and replacing it with a Plexiglas cover $5 \mathrm{~min}$ before the start of the trial. The cover contained a plastic chimney through which the cricket was dropped.

Procedure. The observer started a stopwatch when the cricket was dropped into the home cage and stopped it when the animal ate any of the cricket (eating was defined as sitting on the haunches with the cricket held to the mouth by the front paws while biting or chewing). For at least one member of each species, the observer

Table 2

Average Latency (in sec) to Eat the Cricket and the Percentage of Species Members that Killed

\begin{tabular}{|c|c|c|c|c|c|}
\hline \multirow[b]{2}{*}{ Species } & \multicolumn{2}{|c|}{$N$} & \multicolumn{2}{|c|}{ Latency } & \multirow[b]{2}{*}{$\%$ Kill } \\
\hline & $M$ & $F$ & $M$ & $S E$ & \\
\hline O. leucogaster & 4 & 2 & 8.8 & 1.7 & 100 \\
\hline P. californicus & 3 & 3 & 23.7 & 10.7 & 100 \\
\hline P. maniculatus & 3 & 3 & 129.1 & 94.5 & 83 \\
\hline P. leucopus & 3 & 3 & 140.4 & 92.6 & 83 \\
\hline M. unguiculatus & 3 & 3 & 402.7 & 124.8 & 33 \\
\hline A. cahirinus & 3 & 3 & 407.8 & 121.6 & 33 \\
\hline S. hispidus & 3 & 3 & 600.0 & 0.0 & 0 \\
\hline
\end{tabular}

Note-The column headed $N$ shows the number of subjects in each species differentiated by male $(M)$ and female $(F)$. A logarithmic transformation (base 10) was applied to the latency scores prior to statistical analysis. 
presented up to 10 more crickets (at 2-min intervals) to establish attack topographies and a modal description of the predatory sequence. The observer was instructed to describe the approach (e.g., chase, stalk, pounce), procurement (use of mouth and paws), manipulation before and during eating, orientation of prey while eating, and posture while eating. During assessment of topography, all crickets except the last were removed before ingestion occurred.

\section{Results}

Table 2 shows the mean latency to eat the initial cricket and the percentage of these crickets killed for each species. There were no significant or apparent sex differences, so the distinction between sexes was not used in further analyses. An analysis of variance on the $\log$ (base 10) latency scores showed a significant, overall difference among the species $[F(6,35)=7.18, p<.01]$. A planned contrast of the carnivorous and omnivorous species versus the more herbivorous species showed significantly shorter latencies for the more carnivorous species $[F(1,35)=30.3, p<.0001]$.

In general, the consistency of killing and the latency of eating the cricket were predictable from the field data. The most carnivorous species $(O$. leucogaster) readily killed and ate the crickets with very short latencies. The omnivorous species ( $P$. maniculatus, $P$. leucopus, and $P$. californicus) killed and ate at similar high levels, but generally with longer latencies, especially for $P$. maniculatus and $P$. leucopus. The reaction of the more herbivorous species was noticeably different. Only $33 \%$ or less of each species killed the cricket, although the kills were reasonably quick $(10-40 \mathrm{sec})$. $S$. hispidus failed even to move toward the cricket when it was presented. These results were supported by the significant rankordered correlation between degree of reported carnivory and the average latency to eat the cricket (see Table 3 ). When $P$. californicus was ranked second, $r_{s}(7)=1.00$; when $P$. californicus was ranked fourth, $r_{s}(7)=.89$ (both ps $<.01)$.

We culled from the observer's daily notes and from videotapes of at least one mouse of each species a modal predatory sequence for each species; we also noted frequent alternative responses and a few unique topographies. In addition to providing a general idea of the nature of predatory behavior for each species, these descriptions identified recognizable topographies of responding to the cricket for subsequent comparison with responding to the ball bearing.

o. leucogaster approached the cricket directly and without pause or hesitation. The cricket was "fielded" using some combination of front paws, mouth, and body, depending on the behavior of the prey (see Langley, 1987). No specific behavior was directed at disabling the cricket. Instead, the mouse sat immediately and ate, beginning with the head and often holding the cricket's jumping legs against its body. Motionless damaged prey were picked up with the mouth rather than with the paws.

$P$. californicus were close to $O$. leucogaster in directness and speed of capture, but were neither as adept with their paws nor quite as rapid or sustained in their orientation to the cricket. Following a direct approach, the animal lunged at the cricket mouth first, biting and retreating repeatedly. The paws were outstretched and slightly spread during the lunge. "Boxing" also occurred (a fast pounce-hit with both paws, eyes squinted), which usually stopped the cricket from moving for a time. Stationary prey were picked up with the paws, although the lungebite sequence was sometimes used to dismember the cricket. The mouse sat up to eat and used its paws to rotate the cricket along different axes (including a unique corn-on-the-cob rotation).

$P$. maniculatus and $P$. leucopus approached the cricket slowly with frequent pauses and hesitations, eventually pouncing on the cricket with the forepaws and biting it rapidly on the head and thorax before recoiling. The mouse repeated the pounce-bite-release sequence until the cricket no longer moved, only then assuming the eating posture, most frequently beginning with the head. In approach, the mouse's body was frequently extended, the eyes squinted, and the face wrinkled. If the cricket jumped, the animal recoiled.

$M$. unguiculatus sometimes showed a direct but unhurried approach, and other times appeared to find the cricket by accident. Contact was unpredictable and occurred through a mixture of sniffs, single lunge-bites, paw grabs, and pins with the paws and bite. With experience, the animal showed the latter pattern more frequently. Some-

Table 3

Spearman Rank-Ordered Correlations Between Reported Carnivory and Laboratory Measures of Predatory Responses to Crickets and Moving Ball Bearings ( $\boldsymbol{r}_{\mathrm{t}}$ )

\begin{tabular}{lccccccc}
\multicolumn{1}{c}{ Condition } & $\begin{array}{c}\text { Field } \\
\text { Obs. }\end{array}$ & $\begin{array}{c}\text { Eat } \\
\text { Latency }\end{array}$ & $\begin{array}{c}\text { Baseline } \\
\text { Approach }\end{array}$ & $\begin{array}{c}\text { Baseline } \\
\text { Contact }\end{array}$ & $\begin{array}{c}\text { Operant } \\
\text { Approach }\end{array}$ & $\begin{array}{c}\text { Operant } \\
\text { Contact }\end{array}$ & $\begin{array}{c}\text { Conditional } \\
\text { Mouth }\end{array}$ \\
\hline Reported Carnivory (1) & - & $1.00 \dagger$ & $.88^{*}$ & $.86^{*}$ & $.81^{*}$ & $.75^{*}$ & $.86^{*}$ \\
Reported Carnivory (2) & - & $.89 \dagger$ & .71 & .67 & .69 & $.75^{*}$ & $.89 \dagger$ \\
Cricket Eat Latency & & - & $.88^{*}$ & $.86^{*}$ & $.81^{*}$ & $.75^{*}$ & $.86^{*}$ \\
Baseline BB Approach & & & - & $.95 \dagger$ & .56 & .34 & .56 \\
Baseline BB Contact & & & & - & .51 & .50 & .61 \\
Operant Approach & & & & & - & $.92 \dagger$ & $.83^{*}$ \\
Operant Contact & & & & & & - & $.86^{*}$ \\
Conditional Mouth Contact & & & & & & & - \\
\hline
\end{tabular}

Note-Two orderings of the reported carnivory data were correlated with the remaining measures: (1) $P$. californicus was ranked second. (2) $P$. californicus was ranked fourth. The rest of the correlations in the table were not affected by the ordering of the field observations. Obs. = observations. ${ }^{*} p<.05$. $t p<.01$. 
times the mouse picked up the cricket without disabling it, and sometimes killed it with head bites first. Eating occurred in a sitting posture and usually began head first.

$A$. cahirinus were even more variable in their orientation to the cricket, typically approaching unhurriedly and not directly. Once the cricket was encountered, the animal frequently ran alongside and bit at it without using its paws. With more experience, the mouse sometimes seized the cricket in its mouth and carried it about the cage. Kills were inefficient and often were a by-product of biting at the cricket. Eating occurred while sitting up and was preceded by grasping the cricket in the paws or pulling off appendages while it was on the ground.

$S$. hispidus made no move toward the cricket.

In summary, naive members of all our rodent species, except perhaps $S$. hispidus, were capable of preying on live crickets in characteristic ways. From $33 \%$ to $100 \%$ of the members of each species (except $S$. hispidus) began to eat crickets within 10 min of their first exposure. The capture and disabling of the crickets revealed two additional phenomena. First, there was considerable flexibility in the responses of the rodents to the behavior of the cricket. This adaptive variability appeared to decrease in the more herbivorous mice. Second, there were considerable differences in how cautious a species appeared to be in approaching the crickets. Even without previous predatory experience, approach (when it occurred) was direct and without pause or hesitation in $O$. leucogaster, $M$. unguiculatus and, to a lesser extent, in $P$. californicus and $A$. caharinus. This apparent lack of caution was unrelated to efficiency in killing the crickets (see Table 2), although it may be related to relatively low predatory risk in their selection environment.

As an aside, a cricket's best defense against predation appeared to be to remain motionless until approached, and then to jump into the air. Jumping appeared to confuse all species. Animals often approached and sniffed the area where the cricket last was, but did not look farther until they saw the cricket move where it landed, or they accidentally stumbled on it. In addition, the cricket's jumping response increased pausing and slowed approach in all species except $O$. leucogaster and some $P$. californicus.

\section{EXPERIMENT 2}

The purpose of Experiment 2 was to investigate the relation between species' reactions to moving ball bearings and their degree of reported carnivory and their predation on crickets in Experiment 1. Two predictions were examined. The first prediction was that the extent of interaction with the ball bearing should be related directly to the degree of carnivory across species. This prediction was tested by comparing the reactions of the more predatory species with those of the less predatory species, and by examining the rank-order correlation between carnivory and the extent of interaction with the bearing.
The second prediction was that the topography of interaction with the ball bearing for a particular species should resemble topographies of interaction with crickets in Experiment 1 . This prediction was tested by looking for similarities in both typical and unique topographies of bearing and cricket interaction.

Four prey-naive members of each species were exposed to 10 ball bearings per day under three types of circumstance: ball bearing alone (baseline and extinction), Pavlovian pairing between the ball bearing and a food pellet, and an operant requirement of touching the bearing with nose, paws, or mouth to get food.

\section{Method}

Subjects. Four naive members of each species were used. Two were males and 2 were females in each species except $P$. californicus ( 3 males, 1 female). All subjects were born and raised in the laboratory and had no experience with moving prey. Lab chow, water, supplements, and housing were provided as in Experiment 1.

Apparatus. The apparatus was a sheet metal box, $60 \times 25.5 \times 30 \mathrm{~cm}$, with a Plexiglas roof and front. A modified BRS feeder dispensed .8-cm ball bearings through a floor-level entry hole at one end of the long axis of the box. The floor was slanted away from the entry hole at $5^{\circ}$ and was slanted in from the front and back to provide an open channel leading from the entry hole to the exit hole. The ball bearing rolled on two steel rods at the bottom of the channel. The channel and holes were $8.8 \mathrm{~cm}$ from the front wall of the apparatus. The ball bearing entered the chamber $1.5 \mathrm{sec}$ after the dispenser operated, and it left the apparatus $3.7 \mathrm{sec}$ later. If impeded or carried off and then released, the ball bearing returned to the channel and rolled out of the chamber. A Waltke feeder (Waltke Scientific Enterprises, Bloomington, IN) dispensed 20-mg Noyes pellets into a recessed food tray located $3 \mathrm{~cm}$ to the right of the exit hole and $2.75 \mathrm{~cm}$ above the floor of the chamber. The observer sat $1 \mathrm{~m}$ from the front wall of the apparatus. Data recording and control equipment were located in the same room.

Procedure. The subjects were run in three replications, with members of each species represented in at least two of the replications. Each replication involved the following phases: (1) Pretraining1 day of adaptation to the room and 2-4 days of exposure to the apparatus for 10 min each day with 5 food pellets present in the food tray. Animals continued in this condition until they ate all 5 pellets on a given day. (2) Baseline -4 days on which 10 ball bearings were presented singly on a variable-time 60-sec (VT-60) schedule. (3) Feeder training-1-3 days on which the animal received a total of 12 pellets delivered one at a time. On each day 4 pellets were delivered while the animal was at the hopper, 4 were delivered when the animal had moved away from the hopper more than $10 \mathrm{~cm}$, and 4 more after the animal had moved at least $20 \mathrm{~cm}$ away. Again, the variation in number of days depended on whether the mouse ate the pellets. (4) Pavlovian conditioning-10 days on which 10 ball bearings were presented on a VT- 60 schedule, and food was delivered on the exit of each ball bearing from the apparatus. (5) Operant contact training-12 days on which the animal received food only if it touched the bearing with its nose, mouth, or paws. For 10 of the animals (distributed as a minimum of 1 and a maximum of 2 per species), this condition was preceded by a period of 2-6 days of anti-food-tray training in which the animals received reward only if they did not approach within $5 \mathrm{~cm}$ of the food tray while the ball bearing was in the apparatus. This procedure was used to decrease the food-tray responses before operant training to ensure the possibility of attention to the ball bearing. The procedure made no apparent difference in responding under the operant 
contingency, so it was dropped. (6) Extinction-14 days on which 10 ball bearings were presented on a VT- 60 schedule without food. Following each subject's session, the ball bearings and the apparatus were washed with a weak organic-acid detergent mixture to remove any odors left.

During the presentation of each ball bearing, the primary observer (D.L.W.) coded the animal's responses in terms of a sequence of the categories used for rats by Timberlake et al. (1982), with the added category of food-tray behavior (see Timberlake, 1986). The data reported here include approach (move nose or paw to within $1 \mathrm{~cm}$ of ball bearing), contact (touch the bearing with the nose, paw, or mouth), food-tray (remain or approach to within $3 \mathrm{~cm}$ of the food-tray opening, head toward it), and conditional mouth (the probability of touching the ball bearing with the mouth, given that a contact occurred).

The observer also noted the precise forms of approach and contact to compare them with the form of predatory behavior on the crickets in Experiment 1 . The observer was experienced in coding rats' ( $R$. norvegicus) behavior in ball bearing studies and was paid. Agreement with the first author in training sessions was a minimum of $91 \%$. The observer had no knowledge of the feeding ecology of the rodents or their reactions to crickets and thus was blind to any specific expectation of species differences.

\section{Results and Discussion}

Table 4 shows the mean percentage of trials with an approach to or contact of the bearing, the mean conditional percentage of using the mouth on a contact trial, and mean percentage of trials with head in the food tray while the bearing was present, all as a function of conditions and species. The means were calculated from median scores for each animal over the last 3 days of each condition. In the case of the conditional percentage of mouth contacts, if no contact occurred on a trial, a zero was recorded.

Considering first the approach and contact scores, analyses of variance revealed a significant effect on each measure for species $[F \mathrm{~s}(6,21)=5.29$ and $4.79, p<.01]$, conditions $[F \mathrm{~s}(3,63)=19.03$ and $17.89, p<.01]$, and the species $\times$ condition interaction $[F \mathrm{~S}(18,63)=2.87$ and $3.06, p<.05]$. An analysis of the simple effects of conditions on the approach and contact scores of each species showed increases with training for the four more carnivorous species (O. leucogaster, $P$. californicus, $P$. maniculatus, and $P$. leucopus), but not for the three more herbivorous species. Planned contrasts comparing the approaches and contacts of the more and less carnivorous species revealed much larger scores for the more carnivorous species $[F \mathrm{~s}(1,21)=27.92$ and 25.58 , $p<.0001]$.

A similar but weaker pattern of results was shown for the conditional probability of using the mouth in contacting the bearing. The more carnivorous species had a sig-

Table 4

Mean Percentage of Trials with an Approach to or Contact of the Ball Bearing, Mean Percentage of Contact Trials Involving the Mouth, and Mean Percentage of Trials with Head in the Food Hopper While the Ball Bearing Was Present

\begin{tabular}{|c|c|c|c|c|c|c|c|c|c|c|c|c|c|c|}
\hline \multirow[b]{3}{*}{ Condition } & \multicolumn{14}{|c|}{ Species } \\
\hline & \multicolumn{2}{|c|}{ O. leu. } & \multicolumn{2}{|c|}{ P. cal. } & \multicolumn{2}{|c|}{ P. man. } & \multicolumn{2}{|c|}{ P. leu. } & \multicolumn{2}{|c|}{ M. ung. } & \multicolumn{2}{|c|}{ A. cah. } & \multicolumn{2}{|c|}{ S. his. } \\
\hline & $\boldsymbol{M}$ & $S E$ & $\boldsymbol{M}$ & $S E$ & $\boldsymbol{M}$ & $S E$ & $M$ & $S E$ & $M$ & $S E$ & $M$ & $S E$ & $\boldsymbol{M}$ & $S E$ \\
\hline \multicolumn{15}{|c|}{ Approach } \\
\hline $\begin{array}{l}\text { Baseline } \\
\text { Paired } \\
\text { Operant } \\
\text { Extinction }\end{array}$ & $\begin{array}{l}32.5 \\
15.0 \\
55.0 \\
32.5\end{array}$ & $\begin{array}{l}7.5 \\
6.4 \\
8.7 \\
6.3\end{array}$ & $\begin{array}{l}25.0 \\
27.5 \\
65.0 \\
52.5\end{array}$ & $\begin{array}{r}11.9 \\
7.5 \\
8.7 \\
4.8\end{array}$ & $\begin{array}{l}17.5 \\
32.5 \\
67.5 \\
45.0\end{array}$ & $\begin{array}{r}8.5 \\
8.5 \\
17.0 \\
15.6\end{array}$ & $\begin{array}{l}17.5 \\
25.0 \\
67.5 \\
67.5\end{array}$ & $\begin{array}{r}4.8 \\
8.7 \\
13.2 \\
7.5\end{array}$ & $\begin{array}{l}25.0 \\
27.5 \\
17.5 \\
26.2\end{array}$ & $\begin{array}{r}12.6 \\
11.1 \\
4.8 \\
3.8\end{array}$ & $\begin{array}{l}15.0 \\
12.5 \\
30.0 \\
27.5\end{array}$ & $\begin{array}{l}5.0 \\
4.8 \\
7.1 \\
8.5\end{array}$ & $\begin{array}{r}12.5 \\
2.5 \\
7.5 \\
10.0\end{array}$ & $\begin{array}{l}4.8 \\
2.5 \\
4.8 \\
4.1\end{array}$ \\
\hline \multicolumn{15}{|c|}{ Contact } \\
\hline $\begin{array}{l}\text { Baseline } \\
\text { Paired } \\
\text { Operant } \\
\text { Extinction }\end{array}$ & $\begin{array}{r}20.0 \\
7.5 \\
37.5 \\
35.0\end{array}$ & $\begin{array}{r}8.2 \\
2.5 \\
10.3 \\
10.4\end{array}$ & $\begin{array}{l}15.0 \\
10.0 \\
52.5 \\
37.5\end{array}$ & $\begin{array}{r}9.6 \\
4.1 \\
7.5 \\
10.3\end{array}$ & $\begin{array}{r}7.5 \\
12.5 \\
57.5 \\
42.5\end{array}$ & $\begin{array}{r}7.5 \\
6.3 \\
20.2 \\
11.8\end{array}$ & $\begin{array}{r}2.5 \\
7.5 \\
42.5 \\
52.5\end{array}$ & $\begin{array}{r}2.5 \\
4.8 \\
19.3 \\
16.0\end{array}$ & $\begin{array}{r}10.0 \\
5.0 \\
5.0 \\
5.0\end{array}$ & $\begin{array}{r}10.0 \\
2.9 \\
2.9 \\
2.9\end{array}$ & $\begin{array}{l}0.0 \\
2.5 \\
7.5 \\
0.0\end{array}$ & $\begin{array}{l}0.0 \\
2.5 \\
7.5 \\
0.0\end{array}$ & $\begin{array}{l}5.0 \\
0.0 \\
0.0 \\
0.0\end{array}$ & $\begin{array}{l}2.9 \\
0.0 \\
0.0 \\
0.0\end{array}$ \\
\hline \multicolumn{15}{|c|}{ Conditional Mouth } \\
\hline $\begin{array}{l}\text { Baseline } \\
\text { Paired } \\
\text { Operant } \\
\text { Extinction }\end{array}$ & $\begin{array}{l}45.8 \\
50.0 \\
62.5 \\
50.0\end{array}$ & $\begin{array}{l}20.8 \\
28.9 \\
23.9 \\
28.9\end{array}$ & $\begin{array}{l}20.0 \\
37.5 \\
58.2 \\
60.2\end{array}$ & $\begin{array}{l}20.0 \\
23.9 \\
25.0 \\
20.2\end{array}$ & $\begin{array}{r}6.2 \\
15.0 \\
68.8 \\
59.2\end{array}$ & $\begin{array}{r}6.2 \\
15.0 \\
23.7 \\
19.9\end{array}$ & $\begin{array}{r}0.0 \\
50.0 \\
40.5 \\
48.0\end{array}$ & $\begin{array}{r}0.0 \\
28.9 \\
24.6 \\
20.5\end{array}$ & $\begin{array}{l}0.0 \\
0.0 \\
0.0 \\
0.0\end{array}$ & $\begin{array}{l}0.0 \\
0.0 \\
0.0 \\
0.0\end{array}$ & $\begin{array}{l}0.0 \\
0.0 \\
0.0 \\
0.0\end{array}$ & $\begin{array}{l}0.0 \\
0.0 \\
0.0 \\
0.0\end{array}$ & $\begin{array}{r}25.0 \\
0.0 \\
0.0 \\
0.0\end{array}$ & $\begin{array}{r}25.0 \\
0.0 \\
0.0 \\
0.0\end{array}$ \\
\hline \multicolumn{15}{|c|}{ Head in Hopper } \\
\hline $\begin{array}{l}\text { Baseline } \\
\text { Paired } \\
\text { Operant } \\
\text { Extinction }\end{array}$ & $\begin{array}{r}5.0 \\
62.5 \\
25.0 \\
15.0\end{array}$ & $\begin{array}{r}2.9 \\
13.2 \\
9.6 \\
6.5\end{array}$ & $\begin{array}{r}0.0 \\
65.0 \\
22.5 \\
12.5\end{array}$ & $\begin{array}{l}0.0 \\
8.7 \\
6.3 \\
4.8\end{array}$ & $\begin{array}{r}10.0 \\
72.5 \\
15.0 \\
7.5\end{array}$ & $\begin{array}{l}4.1 \\
7.5 \\
8.7 \\
4.8\end{array}$ & $\begin{array}{r}5.0 \\
65.0 \\
22.5 \\
5.0\end{array}$ & $\begin{array}{r}2.9 \\
15.6 \\
10.3 \\
2.9\end{array}$ & $\begin{array}{r}0.0 \\
52.5 \\
32.5 \\
10.0\end{array}$ & $\begin{array}{r}0.0 \\
14.4 \\
6.3 \\
0.0\end{array}$ & $\begin{array}{r}7.5 \\
70.0 \\
35.0 \\
27.5\end{array}$ & $\begin{array}{r}4.8 \\
12.3 \\
5.0 \\
6.3\end{array}$ & $\begin{array}{r}2.5 \\
10.0 \\
2.5 \\
0.0\end{array}$ & $\begin{array}{l}2.5 \\
7.1 \\
2.5 \\
0.0\end{array}$ \\
\hline
\end{tabular}

Note-All scores are averages of the median score for each animal over the last 3 days of each condition. A zero was recorded for the percentage trials with a mouth contact on days without a contact. Thus, if an animal failed to contact on 2 of the last 3 days of a condition, its median percentage trials with a mouth contact was entered as zero. $O$. $L e u$. is Onychomys leucogaster. P. Cal. is Peromyscus californicus. P. man. is Peromyscus maniculatus. P. leu. is Peromyscus leucopus. M. ung. is Meriones unguiculatus. A. cah. is Acomys cahirinus. S. his. is Sigmodon hispidus. 
nificantly higher probability of mouth contact [planned contrast $F(1,21)=15.20, p<.01$ ]; however, this effect was not significantly affected by the conditioning procedure $[F(3,63)=1.97, p>.10]$. There was a significant interaction of species with conditions $[F(18,63)$ $=1.87, p<.05]$ and a significant interaction of the contrast of more and less carnivorous species with conditions $[F(3,63)=5.86, p<.01]$. However, an examination of the simple main effects of conditions at each species revealed significant effects only for $P$. maniculatus $(p<.05)$.

Table 3 shows the rank-order correlations between reported carnivory, latency to eat the cricket in Experiment 1 , and measures of approach and contact of the ball bearing during baseline and during the operant conditioning phase. It can be seen that reported carnivory and cricket killing correlated significantly with all baseline and operant measures of ball bearing interaction. The baseline measures of approach and contact also correlated significantly among themselves, as did the operant conditioning measures of approach, contact, and mouth contact. However, the correlations between baseline and operant measures of bearing contact, although positive, were not significant. This latter was primarily because $P$. maniculatus and $\boldsymbol{P}$. leucopus showed a relatively large increase in responding under the operant requirement condition, whereas $O$. leucogaster showed a small increase.

An unexpected result of this experiment was the failure to obtain a consistent increase in number of approaches and contacts as a function of the pairing condition alone, a result contrary to that obtained with rats. The head-infood-tray measure reported in Table 4 shows that Pavlovian pairing of the bearing and food did have an effect, but on the probability of going to the food tray rather than to the bearing before food. Apparently the animals did not ignore the bearing when it was paired with food; they simply used it as a signal to approach the food tray.

An analysis of variance showed that food-tray behavior was significantly related to species $[F(6,21)=4.79$, $p<.01]$, but a planned contrast showed no difference between more and less carnivorous species $[F(1,21)=$ $2.08, p>.10]$. There was a large effect of conditions $[F(3,63)=79.79, p<.01]$, and a significant interaction of species $\times$ condition $[F(18,63)=2.19, p<.05]$. A test of simple main effects of conditions at each species level showed significant effects for all but $S$. hispidus. This pattern of results suggests that the interval between bearings (prey items) may have been too short for consistent predatory behavior without a requirement that the bearing be contacted to get food. The size and weight of the bearing may also have exceeded that for typically acceptable prey in the absence of a specific operant requirement.

In summary, the more carnivorous species interacted with the bearing more than the less carnivorous species, both in terms of frequency of trials with an approach or contact, and in terms of contacting with the mouth. Un- der the simple contact requirement, the more omnivorous species (Peromyscus) increased bearing interaction the most, and the more herbivorous species increased the least.

On the basis of daily notes and videotapes of at least one animal from each species, we again determined modal sequences of recognizable topographies of interaction with the ball bearing. We also noted frequent alternative responses and some unique topographies. Table 5 lists the topographies that were similar to those shown to the live cricket. There were many instances of similar complex patterns of interaction with the ball bearings and the crickets (e.g., the wrinkled face approach of $P$. maniculatus and $P$. leucopus, the bite-lunge and boxing of $P$. californicus, and the running and biting behavior of $A$. cahirinus).

However, Table 5 also shows some differences. For example, $O$. leucogaster most often picked up the bearing with its mouth rather than with its paws, the opposite of its behavior with moving crickets. Similarly, $P$. maniculatus and $P$. leucopus frequently picked up the

Table 5

Comparison of Characteristic Sequences and Topographies of Responses to the Cricket and to the Ball Bearing for Seven Rodent Species

Onychomys leucogaster

Similarities: Direct and unhesitant approach to prey. Paw adjustments if prey is not cleanly taken. Animal sits up to chew prey held in paws.

Differences: Bearing is often picked up in mouth first; cricket is picked up in mouth only if immobile.

Peromyscus californicus

Similarities: Direct and unhesitant approach to prey. Repeated lunge-bites with paws outstretched. Boxing (stabbling the prey with both paws). Paws used to rotate prey between chewing bouts with mouth alone, animal in sitting position.

Differences: Cricket carried about in mouth more than bearing.

$P$. maniculatus and $P$. leucopus

Similarities: Slow approach to prey with hesitations and recoils. During approach, body is extended, eyes squinted, nose wrinkled, and ears pulled back. Prey is pounced on with both paws, pinned, and bitten. Animal sits up to chew prey held in paws.

Differences: Pounce-bite sequence repeated less frequently with bearing.

Meriones unguiculatus

Similarities: Unhurried, often not direct, but unhesitant approach. Prey is sniffed and held in place with paw.

Differences: Rarely sits and chews bearing.

Acomys cahirinus

Similarities: Unhurried and not always direct approach. Runs beside prey and bites at it.

Differences: Rarely sits and chews bearing.

Sigmodon hispidus

Similarities: Fails to move in presence of prey.

Differences: Every animal contacted the bearing at least once. No animal ever contacted the cricket. 
bearing in their mouths without pinning it first with the paws. These differences may be related to the different forms of stimuli provided by a smoothly rolling nonreactive bearing, and a reactive struggling cricket.

\section{GENERAL DISCUSSION}

The results supported the possibility that the development and control of species-typical predatory behavior can be studied in the laboratory using artificial prey (Timberlake \& Melcer, 1988). Prey-inexperienced members of seven rodent species showed characteristic and distinct quantitative and topographical differences in predatory behavior in the laboratory. All species (except $S$. hispidus) killed crickets upon initial exposure, but with markedly different speed and technique. All species at some time overtly reacted to the moving bearing, although some responded to the bearing primarily as a signal to go to the food tray, whereas other interacted with it extensively.

Both our hypotheses received strong support. The more carnivorous species (based on reported carnivory) killed crickets faster and more reliably, and interacted more frequently and extensively with the moving bearing. There were also marked similarities in the topography with which each species interacted with the cricket and the bearing (see Table 5). For example, with the exception of $O$. leucogaster, species that tended to use their paws in capturing the cricket also used their paws more in capturing the bearing. Species that did not use their paws in capturing crickets rarely captured the bearing with their paws. This result was not due to an inability of the rodents to use paws in manipulating captured prey.

Together the results support the existence of a speciestypical organization underlying predatory food-getting behavior in these rodents. Prey-inexperienced, laboratoryreared animals interacted with live prey and artificial moving stimuli in similar fashions and at a level predictable from the degree of reported field carnivory for their species. The underlying appetitive organization appeared to include differential sensitivity to moving stimuli, preorganized response components, and susceptibility to modification by learning. Species with diets dependent on consistent intake of moderately quick-moving prey appeared to have a greater interest in moving stimuli and more consistent, effective, and rapidly acquired predatory responses than the more herbivorous species.

\section{Species Considerations}

If we assume that predatory reactions to live and artificial prey index aspects of species-typical appetitive organization, it might be anticipated that the predatory behavior of the more carnivorous species would show more stereotyped components (e.g., Leyhausen, 1979). However, although stereotypy of predatory behavior was present in our data, it occurred in all species. The more salient characteristic of the predatory behavior of the more carnivorous species was the extent and efficiency of its local control. For example, the more herbivorous $A$. $c a$ - hirinus frequently reacted to both live and artificial prey by running alongside and nipping at it, but this behavior was not efficient in subduing either type of prey. On the other hand, $O$. leucogaster showed considerable variation in the form of its interaction with individual crickets, a variation seemingly dependent on closely tracking the behavior of the prey. This species appeared to have several local adjustment "programs" involving coordination of the front limbs, mouth, and body that rarely allowed a cricket to escape (see also Langley, 1987). Such complex local adjustment programs were not engaged by the more predictable ball bearing.

The failure of the bearings to engage local adjustments by $O$. leucogaster may help explain the contrast between their extreme efficiency in dispatching crickets, and their relatively low degree of interaction with the ball bearing. $O$. leucogaster may have more finely tuned perceptual filters for potential prey, especially after some experience with a stimulus. The operation of such filters might quickly downgrade ball bearings from the class of objects appropriate for predation because of the regularity of their motion and their inaccessibility as food items after capture. In partial support of this view, the two least reactive o. leucogaster showed higher interaction with the ball bearing after 5 days of conditioning than after 12 . The use of laboratory pellets as the food reward may also have been less appropriate for controlling predatory responses in a carnivorous animal.

In contrast, the Peromyscus species, especially $P$. leucopus and $P$. maniculatus, interacted more extensively with the bearing than anticipated from their initial cricket killing. Two factors may have contributed. First, like the rat, both species are decidedly opportunistic omnivores, markedly changing the nature of their food intake with time of year and habitat (Wolff et al., 1985). Such opportunists may have a less structured appetitive organization with a larger role for learning than more carnivorous species with restricted food types. Second, both $P$. maniculatus and $P$. leucopus appeared fearful in initial contacts with crickets and ball bearings, which may have obscured their initial predatory interest. In support of this possibility, the present data showed a marked increase in bearing interaction with experience in both species (see also Kreiter \& Timberlake, 1988).

$M$. unguiculatus appeared to be more efficient predators than the other herbivorous species, but their predation was inconsistent and took several forms. In an attempt to better engage any predatory structure, we incrementally shaped 2 animals first to orient, then to approach, and finally to contact the bearing. With this procedure, we found they increased their contacts to an average of $30 \%-40 \%$ of the trials. Members of S. hispidus, $A$. cahirinus, and $O$. leucogaster that we also tried to shape showed no noticeable increase in bearing interaction. The gerbil may be an omnivore that has lost some predatory organization or has a raised threshold or more restricted stimulus filters related to predation, but its responses and sensitivity to eliciting stimuli can be in- 
creased by appropriate shaping (however, apparently not by simple prey experience; see C. J. Brack, 1981; G. L. Brack, 1981).

Finally, the behavior of $S$. hispidus suggested another source of species differences: strength of fear reactions to the environment and especially to the prey. Prior to introduction of the prey, this species moved about its environment and ate food pellets reliably during magazine training in the bearing chamber. After introduction of the bearings or crickets, this species rarely moved or ate again, even over the course of over a month of training. Eliminating the presence of the observer by using a video camera and delaying the start of the session by $1 / 2 h$ following the animal's entry into the apparatus produced no improvement. It appeared that both ball bearing and cricket overwhelmed this species. This immobility probably represents a feature of the animal's behavior in nature, rather than merely an aberration specific to the laboratory.

\section{Alternative Explanations}

Because our evidence is primarily correlational, it is particularly important to evaluate alternative explanations. For example, an argument might be made that the correlations between reported carnivory and laboratory tests were due to species differences in attentional ability or fear, rather than to differences in species-typical predatory organization. However, differences in the ability to attend to the ball bearing is not an adequate explanation, because simple pairing of the bearing with food produced increased attention to the food tray in all species.

Differences in fear or caution also are not adequate explanations of the results. Every effort was made to adapt the animals to the bearing chamber. They were not directly handled, but were allowed to enter the experimental apparatus directly from their home cages, and to return to their cages when the session was over. More importantly, $A$. cahirinus and $M$. unguiculatus were among the most active species in the bearing chamber, steadily running about and sniffing over the course of each session, but with little attention directed to the bearing. On the other hand, $P$. maniculatus and $P$. leucopus moved about very slowly, initially, with many body extensions and pauses; but over sessions they came to interact with the bearing extensively.

\section{CONCLUSIONS}

These data suggest that most if not all rodents have an appetitive organization that facilitates predation in some circumstances (Landry, 1970), and that this organization can be studied in the laboratory using artificial prey (Huntingford, 1984; Timberlake \& Melcer, 1988). The nature of this appetitive organization appears to differ in several ways among species, including the response components available, the perceptual filters involved in triggering and guiding predatory behavior, and the species' susceptibil- ity to learning. In our sample, the most carnivorous species showed sustained orientation to moving cues and welldeveloped predatory subroutines sensitive to local feedback from prey behavior. The more omnivorous species showed stimulus sensitivities and predatory subroutines that appeared to involve an important role for experience (see also Kreiter \& Timberlake, 1988). More herbivorous species showed less sustained stimulus orientation and less efficient motor routines, but still produced predation under some circumstances.

\section{REFERENCES}

BoAkes, R. A., \& JefFery, G. (1979). Automodellaggio e malcomportamento. Ricerche di Psicologia, 10, 53-68.

BRACK, C. J. (1981). Effects of maturation and experience upon a predatory sequence in the Mongolian gerbil (Meriones unguiculatus). Unpublished MS thesis, Purdue University.

Brack, G. L. (1981). The development of cricket-catching behavior in the Mongolian gerbil (Meriones unguiculatus). Unpublished MS thesis, Purdue University.

DrICKAMER, L. C. (1972). Experience and selection behavior in the food habits of Peromyscus: Use olfaction. Behaviour, 41, 269-287.

FLAKE, L. D. (1973). Food habits of four species of rodent on a short grass prairie in Colorado. Journal of Mammalogy, 54, 636-647.

HamiLton, W. J., JR. (1941). The food of small forest mammals in Eastern United States. Journal of Mammalogy, 22, 250-263.

Harrison, D. L. (1972). Mammals of Arabia (Vol. 3), London: Ernest Benn.

HENDRICKSON, R. (1983). More cunning than man: A social history of rats and men. New York: Stein and Day.

Horner, B. E., Taylor, J. M., \& Padykula, H. A. (1965). Food habits and gastric morphology of the grasshopper mouse. Journal of Mammalogy, 45, 513-535.

Houtcooper, W. C. (1978). Food habits of rodents in a cultivated ecosystem. Journal of Mammalogy, 45, 513-535.

HuntingFord, F. A. (1984). Some ethical issues raised by studies of predation and aggression. Animal Behaviour, 32, 210-215.

KARLI, P. (1956). The Norway rat's killing response to the white mouse: An experimental analysis. Behaviour, 10, 81-103.

Kincaid, W. B., CAMERoN, G. N. (1982). Dietary variation in three sympatric rodents on the Texas coastal prairie. Jourmal of Mammalogy, 63, 668-672.

Kreiter, N., \& Timberlake, W. (1988). The form and development of predation on crickets in adults of Peromyscus maniculatus bairdi and Peromyscus leucopus noveboracensis. Joumal of Comparative Psychology, 102, 269-278.

LANDRY, S. O. (1970). The rodentia as omnivores. Quarterly Review of Biology, 45, 351-372.

LANGLEY, W. M. (1987). Specializations in the predatory behavior of grasshopper mice (Onychomys leucogaster and $O$. torridus): A comparison with the golden hamster (Mesocricetus auratus). Journal of Comparative Psychology, 101, 322-327.

Leyhausen, P. (1979). Cat behavior (B. A. Tonkins, Trans.). New York: Garland. (Original work published 1956)

MerRITT, J. F. (1974). Factors influencing the local distribution of Peromyscus californicus in Northern California. Journal of Mammalogy, 55, 102-114.

MEYER, B. J., \& MEYer, R. K. (1944). Growth and reproduction of the cotton rat, Sigmodon hispidus hispidus, under laboratory conditions. Journal of Mammalogy, 25, 107-129.

SCHWENTKER, V. (1979). The gerbil: An annotated bibliography of the gerbil as an experimental animal in medical research. Westbrookfield, MA: Tumblebrook Farm.

SHKOLNIK, A. (1966). Studies in the comparative biology of Israel's two species of spiny mice (Genus acomys). Unpublished doctoral disseration, Hebrew University, Jerusalem. 
Timberlake, W. (1983a). The functional organization of appetitive behavior: Behavior systems and learning. In M. D. Zeiler \& P. Harzem (Eds.), Advances in analysis of behaviour: Vol. 3. Biological factors in learning (pp. 177-221). Chichester, England: Wiley.

Timberlake, W. (1983b). Rats' responses to a moving object related to food or water: A behavior-systems analysis. Animal Leaming \& Behavior, 11, 309-320.

Timberlake, W. (1984). An ecological approach to learning. Learning \& Motivation, 15, 321-333.

TmberLakE, W. (1986). Effect of unpredicted food on rats' subsequent reaction to a conditioned stimulus: "Context blocking" versus conditioned alternative behavior. Animal Leaming \& Behavior, 14, 276-286.

Timberlake, W., \& Lucas, G. A. (in press). Behavior systems and leaming: From misbehavior to general laws. In S. B. Klein \& R. R. Mowrer (Eds.), Contemporary leaming theories: Instrumental conditioning and the impact of biological constraints on learning. Hillsdale, NJ: Erlbaum.
Timberlake, W., \& Melcer, T. (1988). Effects of poisoning on predatory and ingestive behavior toward artificial prey in rats (Rattus norvegicus). Journal of Comparative Psychology, 102, 182-187.

Timberlake, W., WAHL, G., KING, D. (1982). Stimulus and response contingencies in the misbehavior of rats. Joumal of Experimental Psychology: Animal Behavior Processes, 8, 62-85.

Tinbergen, N. (1951). The study of instinct. Oxford: Clarendon Press.

Whitaker, J. O., JR. (1963). Food of 120 Peromyscus leucopus from Ithaca, New York. Joumal of Mammalogy, 44, 418-419.

WhtTaker, J. O., JR. (1966). Food of the Mus musculus, Peromyscus maniculatus bardi, and Peromyscus leucopus in Vigo County, Indiana. Journal of Mammalogy, 47, 473-486.

WolfF, J. O., Dueser, R. D., Berry, K. S. (1985). Food habits of sympatric Peromyscus leucopus and Peromyscus maniculatus. Journal of Mammalogy, 66, 795-98.

(Manuscript received November 13, 1987; revision accepted for publication July 20,1988 .)

\title{
Notices and Announcements
}

\author{
1989 Annual Meeting of the Psychonomic Society \\ Change in Dates
}

The dates of the annual meeting of the Psychonomic Society for 1989 have been changed from Friday-Sunday, November 10-12 to Friday-Sunday, November 17-19.

The corrected schedule for the next four meetings is:

1989-Atlanta, November 17-19

1990-New Orleans, November 16-18

1991-San Francisco, November 22-24

1992-St. Louis, November 13-15 